\title{
Effect of the Application of Aluminium Oxide on Recovery in Enhanced Oil Recovery
}

\author{
Odo Jude Emeka, Onyejekwe Ifeanyi, Anthony Chikwe, Angela Nwachukwu, Okereke Ndubuisi, \\ Oguamah Ifeanyi, Obikaonu Agnes Chidiebere
}

Department of Petroleum Engineering, Federal University of Technology, Owerri, Nigeria

\section{Email address:}

Jude.odo@futo.edu.ng (O.J. Emeka), obikaonuagnes@gmail.com (O. A. Chidiebere)

\section{To cite this article:}

Odo Jude Emeka, Onyejekwe Ifeanyi, Anthony Chikwe, Angela Nwachukwu, Okereke Ndubuisi, Oguamah Ifeanyi, Obikaonu Agnes Chidiebere. Effect of the Application of Aluminium Oxide on Recovery in Enhanced Oil Recovery. Engineering and Applied Sciences. Vol. 6, No. 2, 2021, pp. 41-48. doi: 10.11648/j.eas.20210602.12

Received: August 16, 2020; Accepted: October 21, 2020; Published: April 23, 2021

\begin{abstract}
The use of metallic oxides in enhanced oil recovery in the initial stage seems to significantly enhance the productivity from a well by increasing the sweep efficiency, reduce interfacial tension, and reduce oil viscosity among other factors. However, in later stages of the life of the reservoir, it is observed that the technology brings adverse effects such as reduction in the permeability of the reservoir rock, which may cause decline in production and may lead to the abandonment of the reservoir, although there may be sufficient underlying hydrocarbon. This paper studies the extent of permeability alteration due to the aluminium oxide nano-powder, the total amount of recovery due to aluminium oxide nano-powder. It also compares the performance of aluminium oxide nano powder with other selected nano powders, which are silicon oxide and magnesium oxide. In the experiment, the Core Flooding System was used to simulate reservoir fluid flow in the constructed sand packs. The Enhanced Oil Recovery percentages as well as permeability changes were obtained. From the results, in comparison with traditional water flooding, aluminium oxide as well as silicon oxide and magnesium oxide gave high increase in recovery. However, aluminium produced the greatest recovery increase. A higher permeability change was given by aluminium oxide at higher concentration, while at lower concentration, aluminium oxide gave a lower permeability change.
\end{abstract}

Keywords: Aluminium Oxide, Enhanced Oil Recovery, Metallic Oxide, Permeability Alteration, Recovery, Sand Packs, Core Flooding System

\section{Introduction}

Nanotechnology can be defined as the use and control of materials and material properties at a scale of approximately 1 to 100 nanometres, where unique phenomena empower novel applications [1]. Despite the fact that Nanotechnology is a new advancement in scientific research, the improvement of central ideas occurred over an extensive stretch of time [2]. Nanotechnology has also been applied in the oil and gas industry, such as in Enhanced Oil Recovery Technology, but however has had relatively limited application in the field [1]. The application of nano-technology in Enhanced Oil Recovery (EOR) has been found to be an emerging promising alternative for the existing Enhanced Oil Recovery technologies to improve oil and gas recovery. The beneficial and adverse effects of nano-technology assisted enhanced oil recovery are not thoroughly understood. In this paper the application of aluminum oxide is studied to obtain its actual effect on recovery and permeability alteration.

\section{Background}

Several authors have worked on the use of nanotechnology in oil and gas production:

There are two properties possessed by nanoparticles that make them particularly attractive to the Oil and Gas exploration and production business.

The properties are:

1. Their size

2. Their ability to manipulate their behaviour.

Due to their size, nanoparticles which are accurately designed can flow through a regular reservoir pore space of size 1 micron or below.

By adjusting nanoparticle properties, not only can their 
mobility be improved but also the properties of the fluids injected can be enhanced (for example, rheology, and surface tension and wettability modifiers). Also information can be collected about the environment the particles are exposed to in their path of flow.

In line with the rule of thumb which is based on granular transport, nanoparticles should be 5 to 10 times smaller than the diameter of the openings in the porous media. The primary cause of retention of nanoparticles in the reservoir is the interaction or communication between nanoparticles and the contact surface of the porous rock. [1]

Nanoparticles possess three unique characteristics.

They include:

i. Their small size which enable nanoparticles to be transported into formation pores not accessible to larger particles.

ii. At nano scale, material properties are sized dependent due to the large surface area to volume ratio.

iii. Hence, nanoparticles can be engineered to acquire specific optical, magnetic, interfacial, electrical or chemical properties to accomplish explicit functions.

\subsection{Challenges in the Application of Nanoparticles}

Challenges in the application of nanoparticles include:

i. Lack of properly defined health, safety and environment formalities for safe production and recovery of nanoparticles.

ii. Cost of nanoparticles due large quantity needed. The concluded that since nanoparticles possess a lot larger surface areas than bulk particles, they are a lot more reactive when they in contact with surrounding materials.

Nanoparticles in Enhanced Oil Recovery is engineered to accomplish one or more of the following:

i. Rock Wettability Alteration and Oil-Water Interfacial Tension Reduction. Nanoparticles reduce oil-water interfacial tension and alter rock surface wettability due to their surface reactivity, therefore decreasing the capillary force that the oil phase requires to overcome in order to be mobilized.

ii. Oil Viscosity Reduction and Injection Fluid Viscosity Enhancement. Greater conformance and mobility control capacity that is necessary in enhancing macroscopic recovery efficiency is accomplished through adjusting the viscosity of the injection fluid to match the viscosity of the oil. Nanoparticles possess the ability of improving injection fluid viscosity too as also stated by Haroun et al, 2012. Lau and Yu [3] reported that Aqueous dispersion viscosity increases with decrease in the size of silica nanoparticles as found by Metin et al., 2011, 2012.

iii. Nanoparticles can also stabilize emulsions and foam because of their surface activities which causes injection fluid viscosity improvement. They also stated that aluminium oxide nanoparticles dispersed in brine, were observed to reduce oil viscosity as observed by [4], which can be used for conformance and mobility control. The recovery of heavy oil can be improved via decreasing oil viscosity.

Nanoparticles can accomplish this through two processes:

a. Thermal Conductivity Enhancement of heavy oil. Some nanoparticles show ability of enhancing thermal conductivity and specific heat as reported by Srinivasan $\&$ Shah, 2014. Thermal processes occur in the reservoir rock by electromagnetic heating, taking advantage of injected fluid nano-oxides.

b. In-Situ Upgrading of Heavy Oil. Some nanoparticles chemically crack molecules of heavy oil to accomplish heavy oil in-situ upgrading by serving as nano-scale catalyst as observed by Shokrlu \& Babadagli. The large surface area of nanoparticles improves catalytic performances on hydrogenation and hydrocracking reactions as found by Hashemi et al. in 2014. [3]

\subsection{Factors that Determine Paths of the Solids or Particles}

The paths of the solids or particles are determined by numerous factors such as the shape of the particles and the surface properties, the morphology of the medium, the chemistry of the carrying fluid, the flow field in the pore spaces and the various interaction forces between the particles and the medium. These forces acting together significantly affect the particle transportation, adsorption or deposition and the resulting reduction in the permeability of the porous medium. The various particles can be captured by three primary mechanisms:

i. Adsorption of the Particles, because of the Brownian motion, and the electrostatic interaction between the migrating particles and the solid surface of the pores.

ii. Size Exclusion, when the effective size of the pores are smaller than those of the migrating particles.

iii. Sedimentation or Gravity Settling, when the density of the moving particles and the carrying fluids are very different.

\subsection{Factors Which Affect Permeability Decline}

They are:

i. Flow Rate and Fluid Viscosity. Here, particles under low flow rate settle down very quickly causing severe but shallow damage to the core. While higher flow rates carry particles further, hence damage is averaged along the core leading to greater invasion depth.

ii. Particle Concentration. Gao showed that higher particle concentration leads to more deposition increases tendency of pore throat bridging hence, causing greater damage.

iii. Particle Size. He stated that larger particle sizes have tendency to settle down and block or bridge at pore throat, therefore leading to more damage. [5]

The use of nanoparticle in Enhanced Oil Recovery has shown to be highly effective in improving oil recovery [6]. According to [7], metallic oxides nanoparticles have been shown to be a favorable material that can be easily pass through limestone and dolomite porous media. Aluminum 
oxide nanoparticles show great stability over a wide range of temperature and favorable rheological and flow behavior [8]. According to [9], when a nanoparticle dissolves in an acidic solvent, it increases in its morphology and when it is dissolved in a basic solvent, it decreases in its morphology. Metallic nanoparticles such as aluminum oxide can be transported through oil sand pervious media into the reservoir containing heavy oil [10].

Recent nanomaterials have also proven to possess high strength and high stability when they are subjected to high pressure and high temperature conditions [11].

[12] found that dispersing $\mathrm{Al}_{2} \mathrm{O}_{3}$ nanofluids can change the wettability of sandstone from strongly oil-wet to strongly water-wet. [12] concluded that water wetness increased with reduced nanoparticle size as stated by [1]. The use of nanoparticles in Enhanced Oil Recovery has proven to greatly improve oil recovery [13]. [12] concluded that introducing nanoparticles in brine reduces dynamic interfacial tension.

Nanotechnology makes use of nanoparticles to achieve its purposes. Examples of nanoparticles include fullerenes, graphene, carbon nanotubes, quantum dots, and a variety of polymeric, metallic and metal oxides [14].

Nanotechnology has had gigantic impact in nearly every industry from consumer electronics to healthcare and telecommunication [15]. Nanotechnology has also been applied in the oil and gas industry, such as in Enhanced Oil Recovery Technology, but however has had relatively limited application in the field [15].

From a lab test, [15] test showed that small concentrations of nanoparticles can increase the viscosity of water-based fluids without reasonably affecting their densities and could provide potential enhancement in the efficiency of oil recovery. According to [15], the surface environment is generally incompatible with the stability envelope of a lot of nanoparticles. Protective or active layers can be fabricated around the particles in order to shield them from high temperature, pressure and unfavourable chemicals that are in the reservoir.

The primary cause of retention of nanoparticles in the reservoir is the interaction or communication between nanoparticles and the contact surface of the porous rock [15].

Material/Equipment

i. Sharp Sand: This is sand used for the making the sand packs used in the experiment. The sizes of the sand grains range from 63 to 250 microns.

ii. Nanoparticles: This was the enhanced oil recovery agent used for the experiment. Three types of nanoparticles were used - silicon oxide, aluminium oxide and magnesium oxide.

iii. Industrial Salt: This was used to make the brine solution. $30 \mathrm{~g}$ of salt in $1000 \mathrm{~g}$ of water was used to produce the brine.

iv.Crude oil: This was used for the drainage process as well as the imbibition process.

v. Tap Water: This is clean water which was used to wash sand, make brine solution, etc.
vi.Oven: This was used to dry the wet sand.

vii. Core Flooding System: This was used to simulate reservoir fluid flow in the sand packs. It was also used to measure permeability and oil recovery. It is comprised of

a. The flooding chamber

b. The monitor

c. The back pressure regulator

d. The flow conduits

viii. Aluminium Foil: This was used to produce the sand pack. The aluminium foil was a good container for the sand, because it is a conductor. Hence heat can easily through to sand when heating the sand pack and out of the sand when cooling the sand pack.

ix.Viscometer: This equipment was used to measure the viscosity of brine and crude oil at working temperature of $45^{\circ} \mathrm{C}$ and at ambient temperature.

$\mathrm{x}$. Density Meter: This equipment was used to measure the density of brine and crude oil at the working temperature of $45^{\circ} \mathrm{C}$ and at ambient temperature.

xi.Hack Saw: This was used to cut the aluminium foil into the required lengths of $7 \mathrm{~cm}$.

xii. Weighing Balance: This is instrument was used to weigh the dry and wet masses of the sand packs. It was also used to weigh the masses of sand, salt and nanoparticles.

xiii. Flat Bottom Flask: This was used to mix the brine and also the brine with the nanoparticles.

xiv. Net: This was used to seal the sand packs

xv. Cello tape: This was used to seal the sand packs.

xvi. Measuring Cylinder: This was used to collect the effluents from the core flooding system.

xvii. Cut Water Bottles: This was used to saturate the cores.

\section{Method}

1. Washing The Sand

2. Drying the Sand

3. Sieving the Sand: The sand was sieved with a shale shaker in order to obtain sand grain sizes of range 63 to 250 microns.

4. Cutting The Aluminium Foil:

The aluminium foil was cut at lengths of $7 \mathrm{~cm}$ of 6 pieces. At the length, the sand packs contained in the aluminium foil will easily fit into the core holder. And have adequate space for the piston to travel and create the required overburden pressure.

\section{Soaking The Aluminium Foil:}

This was done to remove the thick paper inside the aluminium foil. This is important because, they would act as an insulator and stop the conduction of heat into and out of the sand packs.

6. Measuring The Salt:

The salt was measured at $30 \mathrm{~g}$ for $1000 \mathrm{~g}$ of water for each sand pack.

7. Producing The Brine:

The salt and water were mixed to obtain the brine for each of the sand packs. 
8. Measuring The Nanoparticles:

The nanoparticles were measure at $0.2 \%$ and at $0.4 \%$ of the mass of brine for each of the sand packs.

9. Producing The Enhanced Oil Recovery Agent:

$30 \mathrm{~g}$ of salt $+1000 \mathrm{~g}$ of water were mixed. Then, $0.2 \%$ of the mass of the brine $(1030 \mathrm{~g})$ were mixed with the brine. Also, $0.4 \%$ of the mass of brine was mixed with the brine, for each of the sand packs.

10. Making The Sand Packs:

The sand packs were made by closing one end of the aluminium foil cylinders with net and cello tape. Then, the sand was packed into the foil. This packing was continued until no more sand could enter the cylinder foil. Then the other end of the foil was sealed as well with net and cello tape. This was done to obtain 6 (six) sand packs. And the sand packs were labelled thus-

A1) $0.2 \%$ Aluminium oxide sand pack

A2) $0.4 \%$ Aluminium oxide sand pack

B1) $0.2 \%$ Silicon oxide sand pack

B2) $0.4 \%$ Silicon oxide sand pack

C1) $0.2 \%$ Magnesium oxide sand pack

C2) $0.4 \%$ Magnesium oxide sand pack

11. Measuring The Dry Weights of the Sand Packs

12. Saturating/Soaking The Sand Packs:

This was done so as to introduce the initial water in the sand packs before drainage, just as in the reservoir. During the water saturation of the cores in the cut water bottle, the top was covered with foil sheet. This was to prevent the entry of air the air if not prevented, will penetrate into the sand pack and cause pore blockage and hence increase inadequate saturation of the sand packs with water.

13. Measuring the Wet Weight of The Sand Packs:

The wet weight of the water-saturated sand packs were measured and recorded.

14. Measuring the Density of the Brine and Crude oil:

The density of brine and crude oil were each measured at the working temperature of $45^{\circ} \mathrm{C}$ and at ambient temperature. The readings were recorded.

15. Measuring the Viscosity of Brine and Crude oil:

The viscosity of brine and crude oil were each measured at the working temperature of $45^{\circ} \mathrm{C}$ and at ambient temperature. This was done by measuring the efflux times taken for each fluid to flow from the upper meniscus to the lower meniscus and then taking the average time. This time is the efflux time which in turn is used to obtain the viscosity.

Use of the Core Flooding System

This is the equipment used to replicate fluid flow in the reservoir.

When the required temperature and pressure condition had been attained, then the flooding was begun.

In laboratory, natural drive cannot be simulated. There, water flooding served as the primary and secondary drive. While EOR-Assisted Water Flooding served as the tertiary drive.

The reservoir processes simulated with the Core Flooding System are:

i. The Drainage Process

ii. The Water Flooding Process (Imbibition Process)

\section{iii. The EOR-Assisted Water Flooding}

\section{The Drainage Process}

In this process, the core holder contained the $0.2 \%$ aluminium oxide sand pack. Crude oil was pumped at the flow rate of $1 \mathrm{ml} / \mathrm{min}$ and allowed to flow from the crude oil chamber into the water-saturated $0.2 \%$ aluminium oxide sand pack. During this process, the water (brine) in the sand pack which was being displaced by the crude oil flowed out of the sand pack through the flow conduits and was collected outside the system with a measuring cylinder. The pumping of the crude oil was continued. After some time, the first drop of crude oil was noticed in the measuring cylinder. The process was continued until there was no further increase in the volume of water collected. When there was no further increase in the volume of water (brine), this marked the end of the drainage process.

The sand pack in the core holder had then become saturated with crude oil.

The water still remaining in the sand pack was referred to as the connate water or initial water saturation.

From Archimedes Principle, volume of fluid displaced is equal to volume of fluid pumped into the sand pack.

Therefore, the total volume of water collected is measured and recorded as the OOIP (Oil Originally in Place) of the sand pack.

The Water Flooding Process (Imbibition Process):

In this process, brine was pumped at the same flow rate of $1 \mathrm{ml} / \mathrm{min}$ and allowed to flow from the brine chamber into the crude oil-saturated $0.2 \%$ aluminium oxide sand pack. Similar to the drainage process, the crude oil in the sand pack which was being displaced by the brine flowed out of the sand pack through the flow conduits and was collected outside the system with another measuring cylinder. The pumping of the brine was continued. During the flooding, logging was started. This meant that the system recorded the $\mathrm{dP}$ across the sand pack after every minute.

The stable dP obtained was used to obtain the initial permeability using Darcy's law:

$$
k=\frac{\mathrm{Q} \mu \mathrm{L}}{\mathrm{A} \Delta \mathrm{P}}
$$

After some time, the first drop of brine was noticed in the measuring cylinder. The time from the start of the water flooding to the time the first drop of brine was noticed in the cylinder was recorded as the water breakthrough time. The process was continued until there was no further increase in the volume of crude oil collected. When there was no further increase in the volume of crude oil, this marked the end of the water flooding process.

The total volume of crude oil collected is measured and recorded as the total recovery from water flooding.

\section{EOR-Assisted Water Flooding}

In this process, brine containing $0.2 \%$ aluminium oxide was pumped at the same flow rate of $1 \mathrm{ml} / \mathrm{min}$ and allowed to flow from the brine containing aluminium oxide chamber into the sand pack. Here, more the crude oil which were not recovered during water flooding were being were collected outside the 
system with another measuring cylinder. The pumping of the brine with silicon oxide was continued. Again, during the flooding, logging was started and the system recorded the $\mathrm{dP}$ across the sand pack after every minute.

The stable dP obtained was used to obtain the initial permeability using Darcy's law:

$$
k=\frac{\mathrm{Q} \mu \mathrm{L}}{\mathrm{A} \Delta \mathrm{P}}
$$

The process was continued until there was no further increase in the volume of crude oil collected. When there was no further increase in the volume of crude oil, this marked the end of the EOR-Assisted water flooding process.

The total volume of crude oil collected is measured and recorded as the additional recovery from EOR-Assisted water flooding.

The three processes, Drainage, Water Flooding and EORAssisted Water Flooding is repeated for the remaining 5 sand packs using the corresponding brine with nanoparticles for the EOR-Assisted Water Flooding.

\section{Results}

The Result obtained from the experiment are as follows:

Working Temperature $=45^{\circ} \mathrm{C}$. Working Pressure $=$ 3000 psig to 3500 psig

\subsection{Formulas used in the Result Analysis}

i. Calculation of Pore Volume

$$
V p=\frac{\text { wet weight }- \text { dry weight }}{\text { density of brine }}
$$

ii. Calculation of Kinematic Viscosity

$$
\begin{aligned}
& \text { Kinematic Viscosity } \\
& \quad=\text { Average Efflux Time } \\
& * \text { Viscometer Constant }
\end{aligned}
$$

iii. Calculation of Dynamic Viscosity

Dynamic Viscosity = Kinematic Viscosity $*$ Density of Fluid

iv.Calculation of Bulk Volume

$$
V b=\text { volume of a cylinder }=\pi r^{2} h
$$

\begin{tabular}{|c|c|c|c|c|}
\hline Fluid & Density $\left(\mathrm{g} / \mathrm{cm}^{3}\right)$ & S.G & ${ }^{\circ} \mathrm{API}\left({ }^{0}\right)$ & Dynamic Viscosity (cP) \\
\hline Brine & 1.0167 & 1.0202 & - & 0.95 \\
\hline Brine (with $0.2 \% \mathrm{Al}_{3} \mathrm{O}_{2}$ ) & 1.0171 & 1.0203 & - & 0.97 \\
\hline Brine (with $0.4 \% \mathrm{Al}_{3} \mathrm{O}_{2}$ ) & 1.0191 & 1.0224 & - & 0.86 \\
\hline Brine (with $0.2 \% \mathrm{SiO}_{2}$ ) & 1.0189 & 1.0221 & - & 1.04 \\
\hline Brine (with $0.4 \% \mathrm{SiO}_{2}$ ) & 1.0183 & 1.0215 & - & 0.94 \\
\hline Brine (with $0.2 \% \mathrm{MgO}$ ) & 1.0146 & 1.0178 & - & 0.96 \\
\hline Brine (with $0.4 \% \mathrm{MgO}$ ) & 0.9996 & 1.0028 & - & 0.91 \\
\hline Crude Oil & 0.9110 & 0.9138 & 22.46 & 60.2 \\
\hline
\end{tabular}

v. Calculation of Porosity

$$
\emptyset=\frac{\text { Pore Volume }}{\text { Bulk Volume }}
$$

vi.Calculation of Permeability

\begin{tabular}{|c|c|c|c|c|c|c|c|}
\hline Composition & $\begin{array}{l}\text { Dry Weight } \\
\text { (g) }\end{array}$ & $\begin{array}{l}\text { Wet Weight } \\
\text { (g) }\end{array}$ & $\begin{array}{l}\text { Length } \\
\text { (cm) }\end{array}$ & $\begin{array}{l}\text { Diameter } \\
(\mathrm{cm})\end{array}$ & $\begin{array}{l}\text { Cross Sectional } \\
\text { Area }\left(\mathrm{cm}^{2}\right)\end{array}$ & $\begin{array}{l}\text { Pore Volume } \\
\left(\mathrm{cm}^{3}\right)\end{array}$ & $\begin{array}{l}\text { Bulk Volume } \\
\left(\mathrm{cm}^{3}\right)\end{array}$ \\
\hline \multirow{2}{*}{ ALUMINIUM OXIDE } & 127.0 & 154.2 & 7.0 & 3.9 & 11.951 & 26.75 & 83.66 \\
\hline & 126.8 & 154.0 & 6.9 & 3.9 & 11.951 & 26.75 & 82.46 \\
\hline \multirow{2}{*}{ SILICON OXIDE } & 134.4 & 161.1 & 7.5 & 3.5 & 9.625 & 26.26 & 72.19 \\
\hline & 120.2 & 147.4 & 7.0 & 3.9 & 11.951 & 26.75 & 83.66 \\
\hline \multirow{2}{*}{ MAGNESIUM OXIDE } & 125.7 & 151.2 & 7.0 & 3.9 & 11.951 & 25.08 & 83.66 \\
\hline & 128.5 & 154.2 & 7.0 & 3.9 & 11.951 & 25.28 & 83.66 \\
\hline
\end{tabular}

$$
k=\frac{\mathrm{Q} \mu \mathrm{L}}{\mathrm{A} \Delta \mathrm{P}}
$$

Table 1. Fluid Properties at ambient temperature.

Table 2. Fluid Properties at working temperature of $45^{\circ} \mathrm{C}$.

\begin{tabular}{lllll}
\hline Fluid & Density $\left(\mathbf{g} / \mathbf{c m}^{\mathbf{3}}\right)$ & S.G & $\left.{ }^{\mathbf{0}} \mathbf{A P I} \mathbf{(}^{\mathbf{0}}\right)$ & Dynamic Viscosity (cP) \\
\hline Brine & 1.0063 & 1.0142 & - & 0.66 \\
Brine (with $0.2 \% \mathrm{Al}_{3} \mathrm{O}_{2}$ ) & 1.0111 & 1.0203 & - & 0.66 \\
Brine (with $0.4 \% \mathrm{Al}_{3} \mathrm{O}_{2}$ ) & 1.0131 & 1.0204 & - & 0.66 \\
Brine (with $0.2 \% \mathrm{SiO}_{2}$ ) & 1.0129 & 1.0221 & - & 0.68 \\
Brine (with $0.4 \% \mathrm{SiO}_{2}$ ) & 1.0123 & 1.0204 & - & 0.66 \\
Brine (with $0.2 \% \mathrm{MgO}$ ) & 1.0066 & 1.0138 & - & 0.68 \\
Brine (with $0.4 \% \mathrm{MgO}$ ) & 0.9678 & 0.9749 & - & 0.61 \\
Crude Oil & 0.8991 & 0.9078 & 22.46 & 19.2 \\
\hline
\end{tabular}

Table 3. Oil Recovery Result. 


\begin{tabular}{lllllll}
\hline Composition & $\begin{array}{l}\text { Porosity } \\
\mathbf{( \% )}\end{array}$ & OOIP $(\mathbf{m l})$ & $\begin{array}{l}\text { Oil Recovered in } \\
\text { Water Flooding }(\mathbf{m l})\end{array}$ & $\begin{array}{l}\text { Oil Recovered } \\
\text { in EOR (ml) }\end{array}$ & $\begin{array}{l}\text { Displacement } \\
\text { Efficiency in WF (\%) }\end{array}$ & $\begin{array}{l}\text { Displacement } \\
\text { Efficiency in EOR (\%) }\end{array}$ \\
\hline \multirow{2}{*}{ ALUMINIUM OXIDE } & 31.98 & 12.8 & 8.8 & 12.0 & 68.75 & 93.75 \\
& 32.44 & 12.0 & 8 & 11.7 & 66.67 & 97.5 \\
\multirow{2}{*}{ SILICON OXIDE } & 36.38 & 12.5 & 8.5 & 10.0 & 68 & 80 \\
& 31.98 & 12.0 & 8 & 11.0 & 66.67 & 91.67 \\
\multirow{2}{*}{ MAGNESIUM OXIDE } & 29.98 & 13.0 & 9 & 10.0 & 69.23 & 76.92 \\
& 30.22 & 12.0 & 8 & 10.0 & 66.67 & 83.33 \\
\hline
\end{tabular}

Table 4. Rock Permeability Result.

\begin{tabular}{lllll}
\hline \multirow{2}{*}{ AGENT } & $\begin{array}{l}\text { SAMPLE } \\
\text { NAME }\end{array}$ & $\begin{array}{l}\text { ABS. PERM. } \\
(\mathbf{m D})\end{array}$ & $\begin{array}{l}\text { EFF. PERM. DURING EOR-ASSISTED } \\
\text { WATERFLOODING (mD) }\end{array}$ & $\begin{array}{l}\text { CHANGE IN } \\
\text { PERMEABILITY (mD) }\end{array}$ \\
\hline 0.2\% Aluminum Oxide & AI & 1214 & 729 & 485 \\
0.4\% Aluminum Oxide & A2 & 1197 & 399 & 798 \\
0.2\% Silicon Oxide & B1 & 1211 & 356 & 855 \\
0.4\% Silicon Oxide & B2 & 729 & 405 & 324 \\
0.2\% Magnesium Oxide & C1 & 911 & 250 & 661 \\
$0.4 \%$ Magnesium Oxide & C2 & 729 & 258 & 471 \\
\hline
\end{tabular}

\subsection{Graphical Analyses}

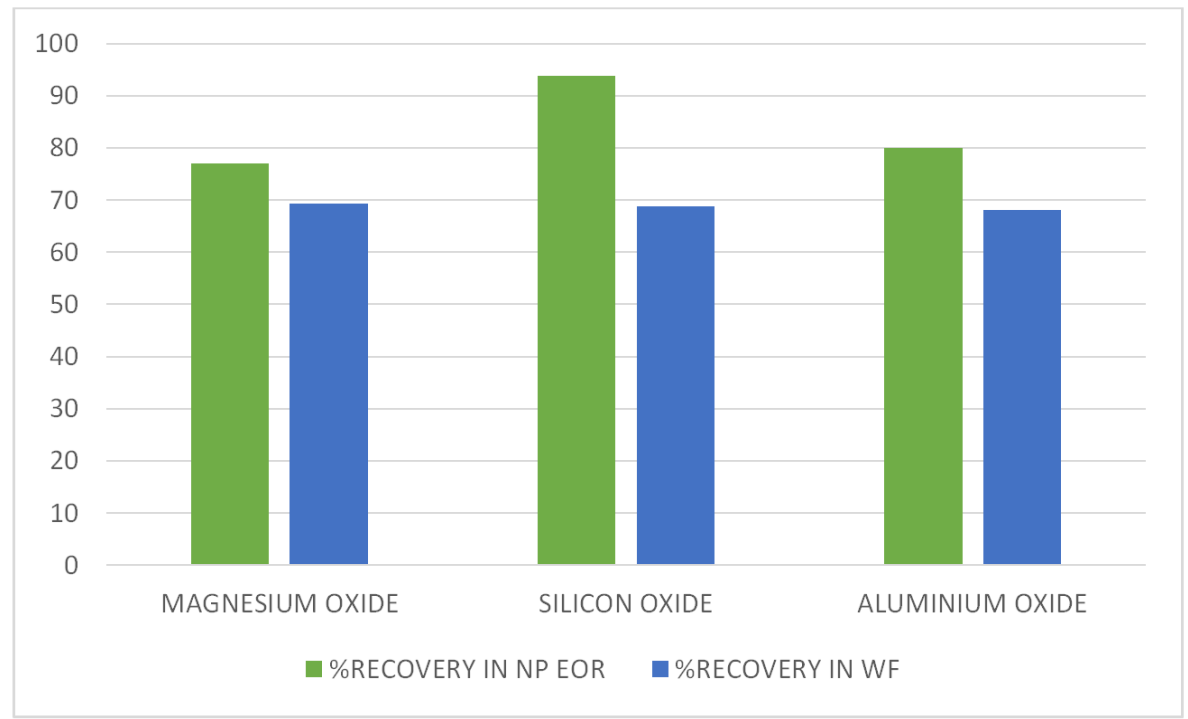

Figure 1. Percentage Recovery with Water Flooding vs with nanoparticle-assisted EOR.

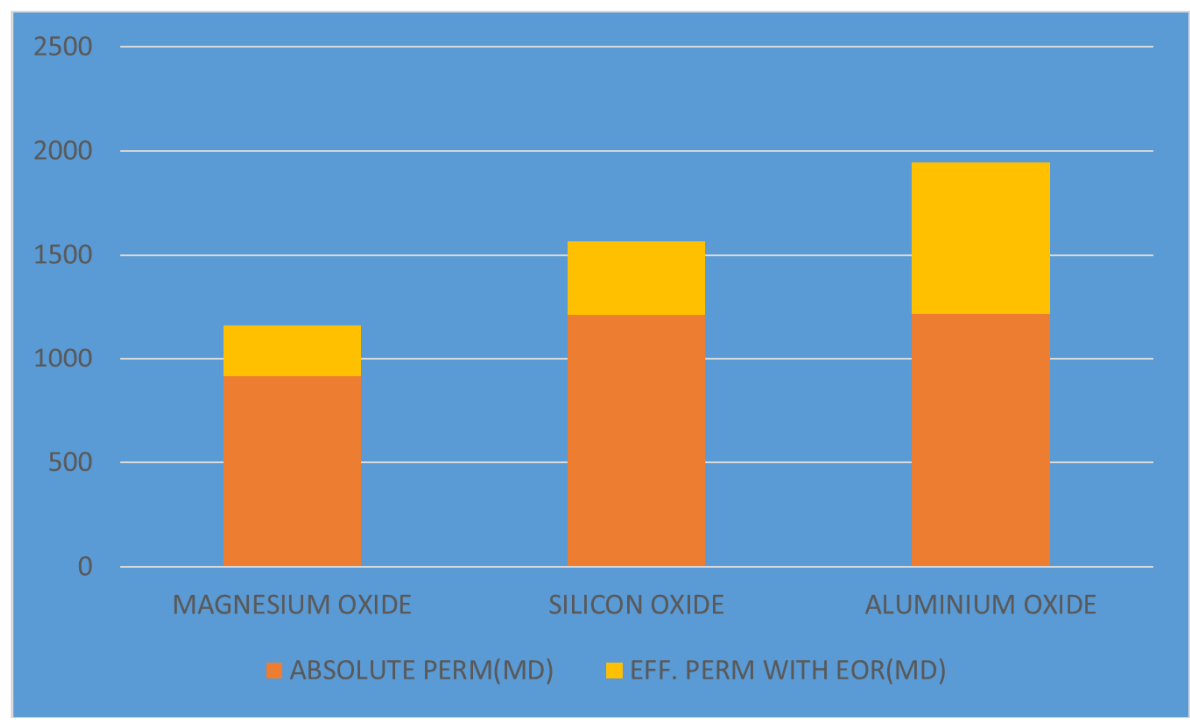

Figure 2. Rock Permeability with Water Flooding vs with Nanoparticle-assisted EOR. 


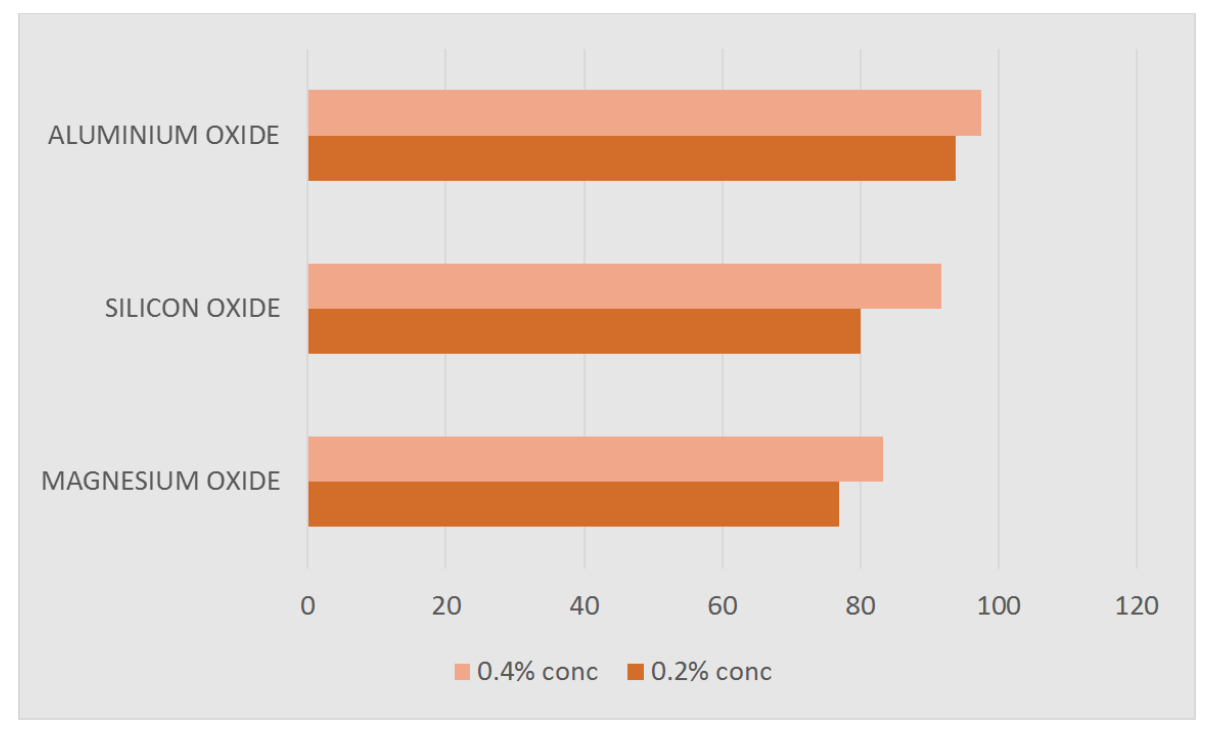

Figure 3. Percentage Oil Recovery in Nanoparticle-Assisted EOR at different concentrations.

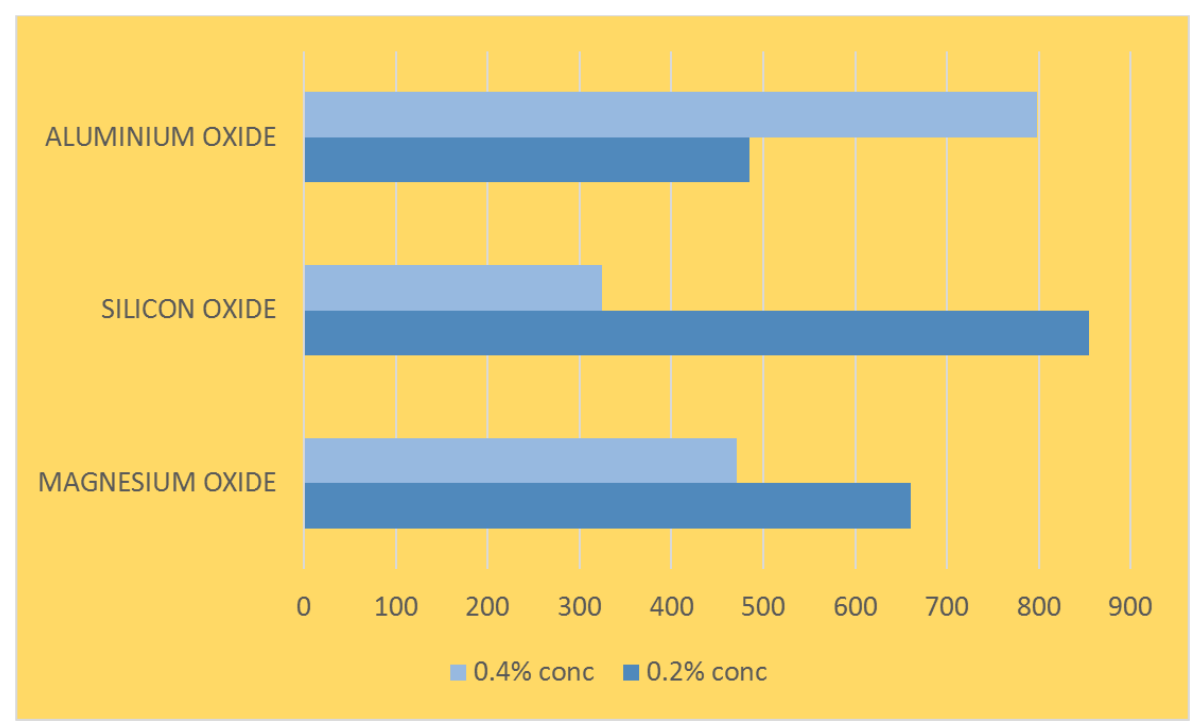

Figure 4. Change in Permeability with different nanoparticle agents at different concentrations.

\section{Discussion}

From the results obtained, the following observation were made:

In terms of recovery:

Aluminium oxide as well as silicon oxide and magnesium oxide gave high increase in recovery in comparison with traditional water flooding. However, aluminium produced the greatest recovery increase. This is in line with [4], who stated that aluminium oxide nanoparticles dispersed in brine reduced oil viscosity, which hence increases oil mobility and increases recovery.

In terms of Permeability Alteration:

At higher concentration, aluminium oxide gave a higher permeability change, while at lower concentration, aluminium oxide gave a lower permeability change. This agrees with [5], who stated that higher particle concentration leads to more deposition increases and greater permeability damage.

It is important to note that aluminium oxide produced a very high recovery increase in comparison with other nanopowders. But however, it caused a high permeability alteration or damage at a higher concentration of $0.4 \%$.

\section{Conclusion}

\subsection{Conclusion}

The study of the effect on recovery and permeability alteration in rock sample using aluminium oxide nanopowder as EOR agent was carried out in this work.

Two other selected nanopowders, silicon oxide and magnesium oxide were also used to compare the performance of the aluminium oxide.

The core flooding system was used to simulate fluid flow in the reservoir.

The EOR agents were used at two different concentrations 
of $0.2 \%$ and $0.4 \%$. While sand packs were used to represent the reservoir rock samples.

From the results obtained and the analysis made, the conclusion from the work include:

i. Aluminium oxide nano-powder improved oil recovery greatly and greater than the other nanopowders.

ii. However, its use caused formation damage or permeability alteration, as the agent accumulate and block pore throats and flow channels in the rock sample (sand pack).

iii. Aluminium oxide caused higher formation damage at higher concentration and lower formation damage at lower concentration, unlike the other nano-powders.

\subsection{Recommendation}

i. From our observation and conclusion, the use of aluminium oxide in EOR is of great benefit to oil and gas production as it greatly increases field oil recovery. Hence, it is recommended to venture more boldly into nanotechnology-assisted enhanced oil recovery.

ii. More funds for research should be allocated by oil companies and the government to further improve nanotechnology application in the oil and gas production.

iii. Aluminium oxide showed very interesting and promising behaviour and result, hence, more study should be made on aluminium oxide use and application in enhanced oil recovery in order to find ways to leverage on its capability to greatly increase oil recovery while finding ways to reduce its damaging effect on the formation.

\section{References}

[1] Kapusta, S., Balzano, L. (2011). Nanotechnology Application in Oil and Gas Exploration and Production. Paper presented at the International Petroleum Technology Conference, 7-9 February, Bangkok, Thailand. p. 1-4.

[2] Wikipedia. (2019). History of Nanotechnology. Retrieved from wikipedia.org: https://en.m.wikipedia.org/wiki/History_of_nanotechnology

[3] Lau, H. C., Yu, M. (2016). Nanotechnology for Oilfield Applications: Challenges and Impact. SPE Paper presented at the International Petroleum Exhibition \& Conference, 7-10 November, Abu Dhabi. p. 1-9.
[4] Ogolo, N. A., Olafuyi, O. A., Onyekonwu, M. O. (2012). SPE Paper presented at the SPE Saudi Arabia Section Technical Symposium and Exhibition. 8-11 April, Al-Khobar, Saudi Arabia. p. 1-5.

[5] Gao, C. (2007). Factors Affecting Particle Retention in Porous Media. Petroleum Engineering Department, Curtin University of Technology, Australia. p. 1-5.

[6] Hogeweg, A. S., Hincapie, R., Foedisch, H., Ganzer, L. (2018). Evaluation of Aluminium Oxide and Titanium Dioxide Nanoparticles for EOR Applications. EAGE Conference and Exhibition 1-2 Copenhagen, Society of Petroleum Engineers.

[7] Bayat, A. E., Junin, R., Shamshirband, S. (2015). Transport and Retention of Engineered Aluminium Oxide, Titanium Oxide and Silicon Oxide Nanoparticles Through Various Sedimentary Rocks Scientific Reports. p5.

[8] Chen, H., Ding, Y., and Tan, C. (2007). Rheological Behaviour of Nanofluids. New Journal of Physics 10.

[9] Vidyapeeth, P., Joob, B., Wiwanitkit, V. (2017). Nanotechnology for Health: A New Useful Technology for Medicine. p5.

[10] Hashemi, N., Pereira -Almao. (2012). Transport Behaviour of Multimetallic Ultradispersed Nanoparticles in an Oil-SandPacked Bed Column at a High Temperature and Pressure Energy Fuels. p1645-1655.

[11] Yang, J., Ji, S., Li, R., Qin, W., Lu, Y. (2015). Advances of Nanotechnologies in Oil and Gas Industries. New York SPE.

[12] Hendraningrat, L., Shidong, L., Torsaeter, O. (2012). A Glass Micromodel Experimental Study of Hydrophilic Nanoparticles Retention for EOR Project. SPE Paper presented at the SPE Russian Oil and Gas Exploration and Production Technical Conference and Exhibition, 16-18 October, Moscow, Russia. p. 4-5.

[13] Alexander, S. H., Rafael E. H., Hendrik F., Leonhard G. (2018). Evaluation of Aluminium Oxide and Titanium Dioxide Nanoparticles for EOR Applications. EAGE Conference and Exhibition 1-2 Copenhagen, Society of Petroleum Engineers.

[14] Sun, X., Zhang, Y, Chen, G., Gai, Z. (2017). Applications of Nanoparticles in Enhanced Oil Recovery: A Critical Review of Recent Progress. College of Petroleum Engineering, China University of Petroleum (East China), Quingdao 266580, China. p. 4-13.

[15] Odedele, T. O. (2014). Synthesis and Application of Nanomaterials in Enhanced Oil Recovery. SPE Paper presented at the SPE Nigerian Annual International Conference and Exhibition, 5-7 August, Lagos, Nigeria. p. 1. 